\title{
Women's Attachment as a Predictor of Pain During Labour and Post-Delivery: a Prospective Observational Study
}

\author{
Vinculação da Mulher como Preditor da Dor Durante o Parto e Após o \\ Nascimento: um Estudo Observacional Prospectivo
}

\author{
José Manuel COSTA MARTINS ${ }^{1,2}$, Carlos Fernandes da SILVA ${ }^{3}$, Marco PEREIRA ${ }^{4}$, Henriqueta MARTINS ${ }^{5}$, \\ Célia OLIVEIRA ${ }^{6}$, Alexandra PUGA ${ }^{1}$, Rui COELHO ${ }^{7}$, Jorge TAVARES ${ }^{8}$ \\ Acta Med Port 2014 Nov-Dec;27(6):692-699
}

\section{ABSTRACT}

Introduction: Labour is considered to be one of the most painful and significant experiences in a woman's life. The aim of this study was to examine whether women's attachment style is a predictor of the pain experienced throughout labour and post-delivery.

Material and Methods: Thirty-two pregnant women were assessed during the third trimester of pregnancy and during labour. Adult attachment was assessed with the Adult Attachment Scale - Revised. The perceived intensity of labour pain was measured using a visual analogue scale for pain in the early stage of labour, throughout labour and post-delivery.

Results: Women with an insecure attachment style reported more pain at $3 \mathrm{~cm}$ of cervical dilatation $(p<0.05)$, before the administration of analgesia $(p<0.01)$ and post-delivery $(p<0.05)$ than those securely attached. In multivariate models, attachment style was a significant predictor of labour pain at $3 \mathrm{~cm}$ of cervical dilatation and before the first administration of analgesia but not of the perceived pain post-delivery.

Discussion: These findings confirm that labour pain is influenced by relevant psychological factors and suggest that a woman's attachment style may be a risk factor for greater pain during labour.

Conclusion: Future studies in the context of obstetric pain may consider the attachment style as an indicator of individual differences in the pain response during labour. This may have important implications in anaesthesiology and to promote a relevant shift in institutional practices and therapeutic procedures.

Keywords: Labor Pain; Labor, Obstetric; Maternal-Fetal Relations; Object Attachment.

\section{RESUMO}

Introdução: O parto é considerado uma das experiências mais dolorosas e significativas na vida de uma mulher. O objectivo deste estudo foi avaliar se o estilo de vinculação da grávida é um preditor significativo da dor experienciada durante o parto e após o nascimento.

Material e Métodos: Trinta e duas grávidas foram avaliadas durante o terceiro trimestre de gravidez e durante o parto. A vinculação no adulto foi avaliada através da Escala de Avaliação no Adulto - Revista. A intensidade da dor de parto foi avaliada através de uma Escala Visual Analógica para a dor durante o parto e após o nascimento.

Resultados: As mulheres com um estilo de vinculação inseguro reportaram maior dor aos $3 \mathrm{~cm}$ de dilatação cervical $(p<0,05)$, antes da administração da analgesia $(p<0,01)$ e após o nascimento $(p<0,05)$ que as mulheres com uma vinculação segura. Nos modelos multivariados, o estilo de vinculação mostrou-se um preditor significativo da dor no parto aos $3 \mathrm{~cm}$ de dilatação cervical e antes da administração da analgesia, mas não na dor percebida após o nascimento.

Discussão: Estes resultados confirmam que a dor de parto é influenciada por factores psicológicos relevantes e sugerem que o estilo de vinculação da mulher pode ser um factor de risco para maior intensidade de dor no parto.

Conclusão: Estudos futuros no contexto da dor obstétrica devem considerar o estilo de vinculação como um indicador de diferenças individuais na experiência de dor durante o parto. Isto pode ter importantes implicações para a Anestesiologia e promover importantes mudanças nas práticas institucionais e procedimentos terapêuticos.

Palavras-chave: Dor do Parto; Trabalho de Parto; Relações Materno-Fetais; Apego ao Objecto.

\section{INTRODUCTION}

Pain is a multidimensional phenomenon ${ }^{1}$ that occurs beyond the physical context and is influenced by culture, individual differences and subjective meanings. ${ }^{2}$ Numerous sociodemographic and physical factors have been shown to be important correlates of the intensity of labour pain. However, the influence of psychological dimensions is also of considerable importance..$^{3-5}$
Regarding demographic and physical factors, studies have revealed significant associations between labour pain and younger age, ${ }^{3,6}$ higher pre-pregnancy body mass index (BMI), ${ }^{6}$ nulliparity, ${ }^{6,7}$ foetal presentation, ${ }^{8}$ dystocia, ${ }^{9}$ higher foetal weight, ${ }^{3,7}$ artificial induction of labour, ${ }^{10}$ history of dysmenorrhoea and menstrual back pain, ${ }^{3,11}$ and participation in childbirth preparation classes. ${ }^{3,6}$

\footnotetext{
1. Departamento de Anestesiologia. Maternidade Alfredo da Costa. Lisboa. Portugal.

2. Faculdade de Medicina. Universidade do Porto. Porto. Portugal.

3. Departamento de Educação. Universidade de Aveiro. Aveiro. Portugal.

4. Faculdade de Psicologia e de Ciências da Educação. Universidade de Coimbra. Coimbra. Portugal.

5. Instituto Superior de Psicologia Aplicada. Instituto Universitário. Lisboa. Portugal.

6. Departamento de Psicologia. Maternidade Alfredo da Costa. Lisboa. Portugal.

7. Departamento de Neurociências Clínicas e Saúde Mental. Hospital de São João. Faculdade de Medicina. Universidade do Porto. Porto. Portugal.

8. Departamento de Anestesiologia. Hospital de São João. Faculdade de Medicina. Universidade do Porto. Porto. Portugal.

Recebido: 02 de Novembro de 2013 - Aceite: 03 de Março de 2014 | Copyright @ Ordem dos Médicos 2014
} 
However, demographic and physical factors do not represent independent influences, as their interaction with psychological factors may contribute synergistically to the painful experience. ${ }^{4}$

Among the psychological factors, there is a growing body of research suggesting the importance of adult attachment in the experience of pain. ${ }^{12-14}$ Although associated with specific sensory events, pain is also a homeostatic emotion, leading to trigger mechanisms for preservation, either by regulating endocrine and autonomic changes or by inducing a degree of transformation of interpersonal relationships. ${ }^{15}$ As pain is often perceived as a form of physical and emotional stress, individuals may elicit attachment behaviours to adapt to or restore a state of security. In initial studies on attachment and pain, Kolb ${ }^{16}$ defined pain complaints as attachment behaviours and identified attachment-related behaviours as an attempt to elicit empathy and responses from caregivers. Therefore, individual differences in the perception of pain reflect an individual's attachment needs, and the ability to regulate negative emotions and to manage threatening or stress-inducing situations. ${ }^{17}$

Attachment styles are determined by infancy and early childhood interactions with primary caregivers, are considered to be stable throughout the lifespan, and are particularly related to emotional regulation and strategies for managing stress-inducing events. ${ }^{18}$ In the context of adult attachment, Bartholomew and Horowitz ${ }^{19}$ proposed a model of attachment styles that is represented by two dimensions: a model of self and a model of others. The model of self ranges from a representation of the self as worthy of love and support to a personal sense of unworthiness associated with anxiety to rejection. The model of others ranges from a representation of others as trustworthy and responsive to an image of others as unreliable and rejecting, resulting in avoidance of close relationships. Based on the intersection of these dimensions, four attachment styles (prototypes) were proposed: a secure style and three insecure styles: preoccupied, fearful and dismissing. When exposed to a pain experience, insecurely attached individuals are less likely to appraise pain more realistically, and tend to view themselves as less able to cope with pain appropriately and to rely on maladaptive affect regulation strategies. ${ }^{12}$

Most studies focused on adult attachment have been conducted in the context of chronic pain, ${ }^{12}$ although the context of acute pain has also begun to be addressed. ${ }^{20}$ Among the studies that have examined how attachment relates to pain, several have reported significant associations between insecure attachment styles and greater pain disability ${ }^{13,21}$ and intensity. ${ }^{21,22}$ Other studies, however, have reported no association between attachment and pain intensity. ${ }^{13,23-25}$ Given these conflicting findings, and given that, to the best of our knowledge, no studies have investigated how attachment is associated with labour pain, this study aimed at assessing the relevance of attachment styles to the prediction of pain during labour and post-delivery.

Therefore, the purpose of this study was to examine the influence of attachment style on the perceived pain intensity during labour and post-delivery. Based on a literature review, we generally hypothesized that an insecure attachment style, in addition to sociodemographic and physical variables, would be significantly associated with higher pain intensity throughout labour.

\section{MATERIAL AND METHODS \\ Participants and procedure}

This prospective, observational and longitudinal study was carried out in compliance with the Helsinki Declaration. Ethical approval to conduct this study was obtained from the Ethics Committee of the Maternity Alfredo da Costa (MAC; Lisbon, Portugal), and the study was also approved by the National Commission of Data Protection. All participants were informed of the purpose of the study, and those women who agreed to participate provided written informed consent. Participants were not compensated for their participation in the study.

Participants were consecutively recruited by convenience sampling during appointments at MAC between April and October 2008. General inclusion criteria were: age $\geq 16$ years and $\leq 40$ years, normal and singleton pregnancy, nulliparous or parous (until third pregnancy), absence of obstetric indices of probable cephalopelvic disproportion, no previous caesarean section for dystocia, absence of psychopathological disorders and substance abuse, absence of contraindications to epidural techniques and a low anaesthetic risk [according to the American Society of Anesthesiologists (ASA)'s Physical Status Classification System (ASA Physical Status I and II)]. Overall, 43 pregnant women recruited by convenience sampling agreed to participate in the study, of which 11 were excluded for not completing all of the phases of the study (completion rate: $74.4 \%$ ). Therefore, 32 pregnant women completed the study.

Participants were assessed at two different time points: in the third trimester of pregnancy and throughout labour. At the first time point, during a face-to-face interview, data were obtained regarding sociodemographic and obstetricgynaecological variables, and participants completed the Adult Attachment Scale - Revised (AAS-R). The second assessment occurred during labour, before and after administration of the epidural analgesic protocol, and included the collection of data regarding labour, delivery, the analgesic technique and pain assessment. After birth, the newborn's weight and Apgar scores at 1 and 5 minutes were also collected.

\section{Analgesic technique}

Epidural ropivacaine $\left(2 \mathrm{mg} / \mathrm{ml}^{-1}\right) \quad$ (Naropeine $^{\circledR}$, AstraZeneca) plus sufentanil $\left(0.5 \mu \mathrm{g} / \mathrm{ml}^{-1}\right)$ in top-ups were used for labour analgesia. The analgesic administration included an initial dose of $10 \mathrm{ml}$ or $12 \mathrm{ml}$ and supplemental doses, varying from $6 \mathrm{ml}$ to $8 \mathrm{ml}$, which were administered on parturients' request. Whenever necessary, with the woman in the sitting position, a perineal dose of $6-8 \mathrm{ml}$, 
without opioids, was administered. When surgical delivery was decided upon, we proceeded with the epidural technique, using higher concentrations of local anaesthetic $\left(7.5 \mathrm{mg} / \mathrm{ml}^{-1}\right)$ in sufficient volumes to obtain a block until T8. All procedures were made by an anaesthesiologist of the research/clinical team.

After epidural analgesia was established, all parturients received an oxytocin infusion (10 $\mathrm{U} .1000 \mathrm{ml}^{-1}$ ) according to the obstetric institutional protocol, with an initial dose of 4 $\mathrm{mU} \cdot \mathrm{min}^{-1}$ and increments of $4-5 \mathrm{mU} \cdot \mathrm{min}^{-1}$ every 2 hours, until a maximum dose of $15 \mathrm{mU} \cdot \mathrm{min}^{-1}$ was attained, adjusted to ensure a medium progression of $1 \mathrm{~cm} \cdot \mathrm{h}^{-1}$ in cervical dilatation.

In the 20 minutes after each analgesic dosage, maternal monitoring included periodic non-invasive blood pressure and heart rate evaluation and the measurement of the sensory block level (loss of sensation to cold) and motor block (based on the modified Bromage scale). These assessments were repeated at 60 minutes and every 2 hours afterward. Labour progress was measured at regular intervals by staff external to the research team. In addition, common side effects, such as nausea, vomiting and pruritus were recorded. During labour, monitoring also included tocodynamometry and continuous foetal heart rate measurements.

\section{Pain}

Pain was assessed with a visual analogue scale (VAS). This study used a VAS with one anchor at 0 , which represented 'no pain at all', and a second anchor at 100 , which represented 'the worst pain imaginable'. The values obtained were recorded immediately after a uterine contraction, considering the average value after two consecutive contractions. The initial VAS score was recorded at $3 \mathrm{~cm}$ of cervical dilatation, and the preanalgesia VAS score represented pain just before each analgesic administration. The residual VAS score indicates the effectiveness of the stabilized analgesic effect (the pain at 30 minutes after analgesic administration), and the postdelivery VAS score represents the level of pain after delivery of the placenta (two consecutive measurements spaced 20 minutes apart). In caesareans, we considered the postdelivery VAS score to be the pain measured when the mother requested the first dose of postoperative analgesia.

\section{Attachment}

Adult attachment was assessed with Adult Attachment Scale - Revised (AAS-R). ${ }^{26,27}$ This measure consists of 18 items answered on a scale of 5 points (from $1=$ Not at all characteristic of me to $5=$ Extremely characteristic of me) and organized into three dimensions: Anxiety, Comfort with proximity and Trust in others. The dimension Anxiety and the aggregation of two dimensions Comfort with proximity and Trust in others (conceptually similar to avoidance) allow the classification of the subject into one of four attachment styles, based on the prototypes of Bartholomew and Horowitz: ${ }^{19}$ a secure style and three insecure styles: preoccupied, fearful and dismissing. According to the scoring protocol, participants were assigned to respective attachment styles based on whether their scores were above or below the midpoint, presenting higher or lower scores for Anxiety and Comfort with proximity/Trust in others.

\section{Statistical analysis}

Data analyses were conducted with IBM SPSS, version 20.0. Descriptive statistics with means and standard deviations ( $S D s$ ) were reported for continuous variables, and frequencies were determined for categorical variables. Mann-Whitney $U$ test and $a \chi^{2}$ analysis were used to examine the relationship between attachment style and continuous and categorical variables, respectively. The association between study variables was examined using Pearson's correlations. Predictors of labour pain were examined in a hierarchical multiple regression (HMR) analysis. Potential confounders, identified as being significantly associated or theoretically linked to the dependent variables, were entered into the multivariable model in the first step. As suggested by Cohen et $a^{28}$ the effect size that was attributable to the increment in $R^{2}$ ( $f^{2}$ for multiple regression) was also calculated (small: Cohen's $f^{2} \geq 0.02$; medium: Cohen's $f^{2}$ $\geq 0.15$; large: Cohen's $f^{2} \geq 0.35$ ). The level of significance (two-tailed) was set at $<0.05$.

\section{RESULTS}

\section{Participant characteristics}

The study sample consisted of 32 pregnant women in the third trimester of pregnancy (median: 28 weeks), with a mean age of 31.31 years (range: 16-44) and a mean education level of 11.09 years (range: 4-17). Most women were married or cohabiting (75\%), and the majority did not participate in childbirth preparation classes (90.6\%). The sociodemographic, obstetric-gynaecological and newborn characteristics are summarized in Table 1. The women with complete data and the excluded women did not differ in any study variables.

The distribution of attachment styles for the sample was as follows: 22 women (68.8\%) were classified as secure, 5 (15.6\%) as fearful, $2(6.3 \%)$ as preoccupied and $3(9.4 \%)$ as dismissing. Given that few participants were identified as having fearful, dismissing or preoccupied attachment styles, the participants were categorized into two attachment styles: secure and insecure (the latter consisting of preoccupied, fearful and dismissing participants). No significant differences were identified between women with secure and insecure styles in terms of sociodemographic, obstetric and newborn characteristics.

Most labour began spontaneously (83.3\%), and all analgesia started in the first stage of labour, with a cervical dilatation of 3-4 cm. No cases of occiput-posterior presentation or an Apgar score $<7$ at the first or fifth minute were observed. Moreover, no side effects were observed.

\section{Attachment style and pain during labour}

The comparison of pain scores according to attachment 
Table 1 - Sociodemographic, obstetrical-gynaecological and newborn characteristics $(n=32)$

\begin{tabular}{lcc}
\hline & Mean (SD) & Range \\
\hline Age (years) & $31.31(6.16)$ & $16-44$ \\
Education (years) & $11.09(4.11)$ & $4-17$ \\
BMI pre-pregnancy $\left(\mathrm{kg} \cdot \mathrm{m}^{-2}\right)$ & $23.31(3.54)$ & $18.86-33.81$ \\
Duration of labour (min) & $534.43(238.59)$ & $115-840$ \\
Newborn weight (g) & $3158.78(313.44)$ & $n(\%)$ \\
\hline & $14(43.8)$ & $2410-4000$ \\
\hline Nulliparous & $10(31.3)$ \\
Menstrual back pain & $7(21.9)$ \\
Intense dysmenorrhoea & $3(9.4)$ \\
Childbirth training program & $6(18.8)$ \\
Dystocia & $6(18.8)$ \\
Oxytocin use before analgesia & \\
\hline Mode of delivery & $21(65.6)$ \\
\hline$\quad$ Vaginal & $3(9.4)$ \\
Instrumental & $8(25.0)$ \\
\hline Caesarean & & \\
\hline
\end{tabular}

style revealed significant differences in most VAS scores $(p<0.001)$. Women with an insecure attachment style reported more pain at $3 \mathrm{~cm}$ of cervical dilatation, just before the first, second and third administrations of analgesia and at post-delivery. In addition, significant differences were also found in the residual VAS scores (Table 2).

Throughout labour, a significant effect of time was identified regarding pain intensity, $F(2,29)=877.01, p<$ 0.001 . Overall, reported pain before the first administration of analgesia was significantly greater than pain reported at 3 $\mathrm{cm}$ of cervical dilatation. Post-delivery pain was significantly lower than pain reported in the previous assessment points (Fig. 1). The interaction between time and attachment style was not statistically significant, $F(2,29)=1,17, p=0.325$.

\section{Correlates of labour pain}

Several analyses were conducted to explore the associations between pain scores, attachment styles and the sociodemographic and clinical variables (Table 3). Overall, older age and a history of menstrual back pain were significantly associated with higher pain scores postdelivery. In addition, an insecure attachment style was significantly correlated with greater pain at $3 \mathrm{~cm}$ of cervical dilatation and before the first administration of analgesia.

\section{Predictors of pain during labour and at post-delivery}

The results showed that, controlling for the covariates, higher education $(\beta=0.33, p=0.040)$ and an insecure attachment style $(\beta=-0.44, p=0.009)$ were significant predictors of the initial VAS scores. The model was statistically significant, $F(4,27)=3.90, p=0.013$ (adjusted $\left.R^{2}=0.27\right)$. The effect size attributable to the addition of attachment style [Cohen's $f^{2}$ ] was 0.29.

Regarding VAS scores before the first administration of analgesia, the model was also statistically significant, $F(3$, $28)=6.75, p=0.001$ (adjusted $R^{2}=0.36$ ), and attachment style was the only significant predictor $(\beta=-0.58, p=0.001)$. The effect size attributable to the addition of attachment was 0,53 . More specifically, an insecure attachment style was significantly associated with greater labour pain.

Finally, regarding the post-delivery pain scores, the final model was statistically significant, $F(4,27)=3.66, p=0.017$ (adjusted $R^{2}=0.26$ ). Only age was a significant predictor ( $\beta=0.41, p=0.039)$; that is, older women were more likely to report greater pain post-delivery. Attachment style was not significant $(\beta=-0.30, p=0.068)$ (Cohen's $\left.f^{2}=0.14\right)$.

\section{DISCUSSION}

Labour pain is experienced at the end of a critical phase of a woman's life cycle. Together with physiological changes, significant psychological and social transformations also occur. ${ }^{29}$ In this context, these changes derive not only from the experiences of the mother but also from the mental representations originating from the early stages of the individual's development and from her interactions with attachment figures. ${ }^{30}$ Based on this premise, we hypothesized that women's attachment would have an impact on the experience of pain during labour, particularly given that pain is an intense stress that can mobilize internal resources anchored in the attachment style of each woman. Considering that, to the best of our knowledge, the link between attachment and labour pain were not the subject of any research, and given that the experience of labour can be a stressful event that can impact both women's health and their relationships with significant others, ${ }^{31,32}$ this study contributes to the study of adult attachment in the context of pain.

Throughout labour, an effect of time on pain scores, resulting from the combination of nociception rhythm and 


\begin{tabular}{|c|c|c|}
\hline & Mean (SD) & Mann-Whitney U \\
\hline VAS initial (mm) & & $57.00^{*}$ \\
\hline Secure $(n=22)$ & $53.18(19.24)$ & \\
\hline Insecure $(n=10)$ & $71.30(20.42)$ & \\
\hline VAS pre-analgesia $1(\mathrm{~mm})$ & & 32.50 ** \\
\hline Secure $(n=22)$ & 87.91 (7.39) & \\
\hline Insecure $(n=10)$ & $97.50(21.73)$ & \\
\hline VAS pre-analgesia $2(\mathrm{~mm})$ & & $10.50^{* *}$ \\
\hline Secure $(n=17)$ & $84.47(9.01)$ & \\
\hline Insecure $(n=7)$ & $96.86(4.41)$ & \\
\hline VAS pre-analgesia 3 (mm) & & $4.50^{\star \star}$ \\
\hline Secure $(n=10)$ & $77.10(7.56)$ & \\
\hline Insecure $(n=6)$ & $91.50(4.09)$ & \\
\hline VAS pre-analgesia $4(\mathrm{~mm})$ & & 5.00 \\
\hline Secure $(n=3)$ & $79.00(16.52)$ & \\
\hline Insecure $(n=5)$ & $88.60(4.93)$ & \\
\hline VAS residual 1 (mm) & & $51.00^{*}$ \\
\hline Secure $(n=22)$ & $13.36(14.92)$ & \\
\hline Insecure $(n=10)$ & $24.70(11.75)$ & \\
\hline VAS residual 2 (mm) & & 17.50 ** \\
\hline Secure $(n=17)$ & $7.35(8.16)$ & \\
\hline Insecure $(n=7)$ & $18.14(6.54)$ & \\
\hline VAS residual 3 (mm) & & 21.00 \\
\hline Secure $(n=10)$ & $6.70(10.57)$ & \\
\hline Insecure $(n=6)$ & $11.83(13.39)$ & \\
\hline VAS residual 4 (mm) & & 6.50 \\
\hline Secure $(n=3)$ & $14.67(14.50)$ & \\
\hline Insecure $(n=5)$ & $11.00(8.28)$ & \\
\hline VAS post-delivery (mm) & & $59.50^{*}$ \\
\hline Secure $(n=22)$ & $14.50(12.55)$ & \\
\hline Insecure $(n=10)$ & $22.40(10.08)$ & \\
\hline
\end{tabular}

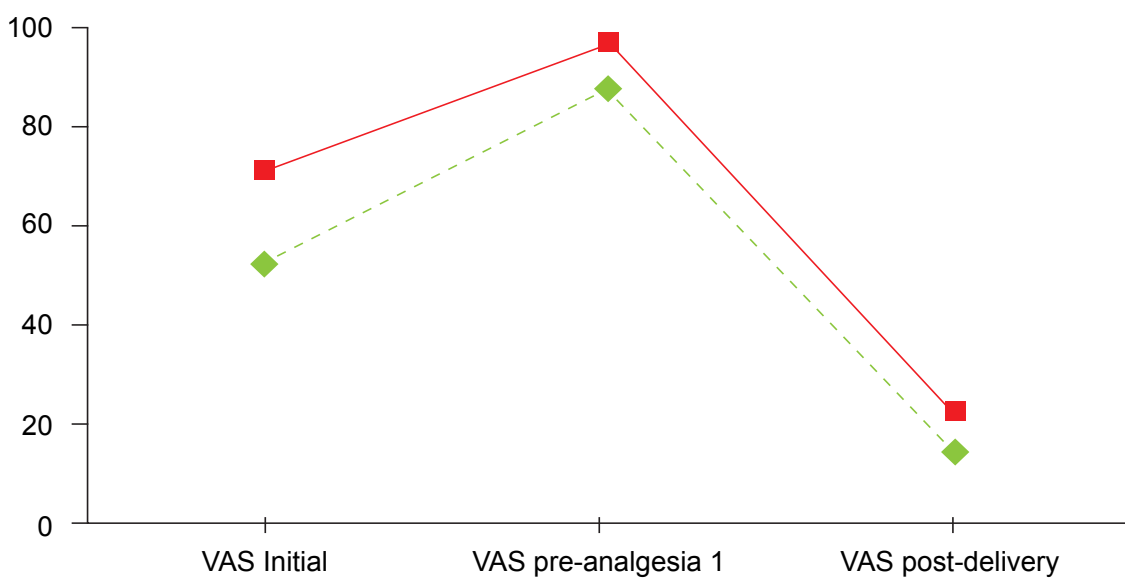

Secure

Figure 1 - Reported pain throughout labour and at post-delivery, by attachment style 
Table 3 - Intercorrelations of the study variables

\begin{tabular}{|c|c|c|c|}
\hline Variables & VAS initial & VAS pre-analgesia 1 & VAS postpartum \\
\hline VAS initial & - & & \\
\hline VAS pre-analgesia 1 & $0.55^{\text {** }}$ & - & \\
\hline VAS postpartum & $0.54^{* *}$ & $0.67^{\star \star \star}$ & - \\
\hline Age & 0.21 & 0.00 & $0.39 *$ \\
\hline Education & 0.30 & 0.06 & -0.13 \\
\hline Parity & 0.05 & 0.01 & 0.22 \\
\hline Menstrual back pain & 0.25 & 0.33 & $0.37^{*}$ \\
\hline Intense dysmenorrhoea & 0.12 & 0.22 & 0.06 \\
\hline Dystocia & 0.19 & -0.11 & -0.04 \\
\hline Pre-pregnancy BMI & 0.08 & 0.14 & 0.19 \\
\hline Childbirth training program & -0.11 & 0.03 & -0.13 \\
\hline Oxytocin use before analgesia & 0.01 & -0.08 & -0.13 \\
\hline Newborn birth weight & 0.14 & -0.03 & 0.04 \\
\hline Attachment style & $-0.41^{*}$ & 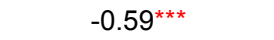 & -0.30 \\
\hline
\end{tabular}

Note: Parity ( 0 = Nulliparous, 1 = Multiparous); Menstrual back pain ( $0=$ No, $1=$ Yes); Intense dysmenorrhoea $(0=$ No, $1=$ Yes); Dystocia $(0=$ No, $1=$ Yes); Oxytocin use before analgesia $(0=$ No, $1=$ Yes $)$; Childbirth training program $(0=$ No, $1=$ Yes $)$; Attachment style $(0=$ Insecure, $1=$ Secure $)$

* $p<0.05 ;{ }^{* *} p<0.01 ;{ }^{* *} p<0.001$

pharmacological action, was observed. Higher scores before the epidural resulted from increasing uterine contractility and cervical dilatation. ${ }^{33}$ After this initial phase, during the analgesic effect, the pain levels declined progressively at the different assessments, despite the greater uterine activity, which reveals the efficacy of the epidural analgesia. ${ }^{34}$ The pharmacodynamic and pharmacokinetic properties of the ropivacaine plus sufentanil solution used in this study dictate an analgesic pattern characterized by sensory-motor differentiation of the local anaesthetic ${ }^{35}$ and a fast instillation of the therapeutic effect, depending on the high lipid solubility of the opioid. ${ }^{36}$ This aspect allows the progressive control of pain as parturients receive additional doses.

The most significant result of this study is that an insecure maternal attachment style was significantly associated with more severe pain both before and during the administration of epidural analgesia. Regarding the initial pain scores, this finding is particularly relevant because it results from the experienced pain during a concrete organic event, related with the pain at the end of the latent phase of the first stage of labour, which is common to all participants $(3 \mathrm{~cm}$ of cervical dilatation). However, a similar pattern (i.e., more pain among insecure women) was observed throughout labour, when the women requested analgesia, and even at the post-stabilized analgesic effect (residual scores) and at post-delivery. In a multivariate analysis, attachment style was a significant predictor of the initial VAS and VAS pre-analgesia 1 scores but was not significant postdelivery. These results correspond to the central purpose of this study and are consistent with our initial predictions, suggesting that individual differences in the perception and expression of pain reflect a person's attachment needs, ability to regulate negative emotions ${ }^{17}$ and different abilities to cope with pain. ${ }^{24}$ Together, these results seem to depict attachment insecurity as a potential risk factor which can lead to poor coping with pain and maladjustment; and attachment security as a more adaptive trait and an important inner resource in the face of stress-inducing events, allowing the individual to positively appraise stressful events and turn to others for support and comfort. Although unexpected, the lack of a significant association between attachment style and post-delivery pain may result from differences in the experience of this important period (the first mother-baby contact), as it is possible that the pain experienced may be influenced by positive emotions that usually characterize the early postpartum period. ${ }^{37}$

Based on the results of our study, older age was significantly associated with higher post-delivery pain but not with intrapartum pain. The post-delivery period, although not usually assessed, is a very early stage after the birth of a child that we believe can be included in the psychobiological experience of birth. Regarding the association between mothers' age and pain, studies have commonly reported a painful experience until expulsion of the foetus, suggesting a negative correlation between these variables. ${ }^{3,6}$ However, this association is not consistent, as other studies did not report significant associations between age and pain intensity. ${ }^{38,39}$ An alternate explanation for this finding may be the fact that, in our study, older women were more likely than younger women to have a caesarean delivery. Since there is evidence showing that women with cesarean deliveries appeared to have more pain, ${ }^{40}$ it is possible that the type of delivery may have contributed to this association between older age and greater post-delivery pain. It is also likely that the influence of age may be multidetermined, since the lower perception of pain in advanced ages may 
relate to the neuronal aging, ${ }^{41}$ and in younger ages a more intense pain may be influenced by a higher psychological vulnerability ${ }^{42,43}$ and also from different educational and socioeconomic conditions. ${ }^{44}$ Given this inconsistency further studies should examine more comprehensively the association between age and pain.

A multivariate analysis also indicated that higher education was significantly associated with greater pain at $3 \mathrm{~cm}$ of cervical dilatation, which is not consistent with most findings in the literature, ${ }^{6,39}$ suggesting that poor knowledge and/or misinformation may intensify the perceived pain. The conflicting results are most likely due to the multidimensional nature of this variable. ${ }^{12}$ Indeed, recent studies showed that Western parturients with higher education have a lower tolerance for pain because of an overestimation of medication. ${ }^{45} \mathrm{~A}$ history of menstrual back pain was associated with higher post-delivery pain scores. This finding, which was only significant in post-delivery pain, was expected to occur throughout labour, ${ }^{11}$ given the biochemical mediation of prostaglandins in both the manifestations of dysmenorrhoea and uterine contractility. ${ }^{46}$ However, we also acknowledge that among these women, menstrual back pain may represent a consequence of more intense myometrial contractility in the uterine recovery phase. This pain may be due to an interaction between endogenous prostaglandins and the exogenous oxytocin commonly used in vaginal and caesarean deliveries. ${ }^{47}$

This study has several methodological strengths. First, the multidimensional nature of pain imposes difficulties on pain assessment. In this context, we preferred a naturalistic, observational method that did not interfere with the overall clinical environment, considering that regular assessments, determined by rigid time intervals or concrete cervical dilatations, cannot reveal the individual oscillations and may represent the intrusion of a researcher, which could interfere with the experience of pain. ${ }^{48}$ Thus, the VAS was used in concrete situations: before the administration of analgesia, after the stabilization of the analgesic effect and postdelivery. Second, the assessment of adult attachment was conducted during the third trimester of pregnancy, as there is evidence that psychological variables are more accessible during this period..$^{49}$ Additionally, the underlying longitudinal design of this study allowed us to more clearly clarify the directionality of the association between attachment and our main outcomes. Finally, regarding the classification of attachment into categories versus dimensions, we believe that categories can be helpful in clinical settings. These categories may aid clinicians in tailoring interventions based on an understanding of individuals' differences and therefore allow for rapid clinical decision-making. ${ }^{50}$

However, some limitations should also be acknowledged when interpreting the findings of this study. First, a convenience sampling method was used, and the available participants may not be representative of the pregnant population. Second, the small sample size limits the strength of the conclusions about the techniques applied to test the hypotheses of the study and limits the study's power to detect small but potentially important differences. Additionally, in the longitudinal analysis, as during labour a low number of women required more than two analgesic administrations, we only considered the three pain scores that included the entire sample. Accordingly, it is important to replicate this study with larger samples to confirm and further clarify the findings reported herein. Third, attachment style was assessed using a self-report measure. Because attachment reflects a person's subjective perceptions of close relationships, participants may be vulnerable to reporting bias. Fourth, the combination of styles into secure and insecure categories was performed for practical reasons, particularly because of the small number of women with fearful, preoccupied and dismissing styles. Further studies on large samples may indicate more specific associations between each of the styles and the experience of labour pain. Finally, other variables that might influence attachment scores, such as the presence of anxiety, were not assessed. As such, the generalizability of our findings may be limited.

\section{CONCLUSION}

To summarize, a woman's attachment style is a factor of undeniable interest in the psychological approach to pregnancy, contributing to a better understanding of labour pain. Our findings support the attachment model as a reliable framework with the potential to identify those women at high risk of suffering from more pain during childbirth, of poorly coping with pain, but also of developing trauma symptoms, which are also likely to occur following childbirth. ${ }^{51,52}$ Additionally, these findings may also translate into relevant clinical implications in the obstetric care. Indeed, if attachment insecurity contributes to poor adjustment to pain or development of maladaptive coping strategies, then this may lead to early intervention and treatment opportunities. Such approaches may include: modifying the appraisal of pain (to see it as less threatening), increasing women's insight about their own attachment style, and modifying some associated cognitive, emotional and behavioural strategies that may be dysfunctional, in order to increase their personal control and self-efficacy. Thus, attachment must be considered in future studies of obstetric pain and in anaesthesiology practice as an indicator of individual differences in the pain response to labour. In addition, we believe that these results can promote a major shift in institutional practices and therapeutic procedures, in which pregnancy should be recognized as a complex process of not only biological changes but also of psychological reorganization.

\section{CONFLICTS OF INTEREST}

The authors report no conflicts of interest.

\section{FUNDING SOURCES}

This study received no funding from any public, commercial, or not-for-profit sectors. 


\section{REFERENCES}

1. Merskey $\mathrm{H}$, Bogduk $\mathrm{N}$. Classification of chronic pain: descriptions of chronic pain syndromes and definitions of pain terms. Seattle: IASP Press; 1994.

2. Le Breton D. Anthropologie de la douler. Paris: Éditions Métailié; 1995.

3. Melzack R, Kinch R, Dobkin P, Lebrun M, Taenzer P. Severity of labour pain: influence of physical as well as psychologic variables. Can Med Assoc J. 1984;130:579-84.

4. Lowe NK. The nature of labor pain. Am J Obstet Gynecol. 2002;186:S1624.

5. Curzik D, Jokic-Begic N. Anxiety sensitivity and anxiety as correlates of expected, experienced and recalled labor pain. J Psychsom Obstet Gynaecol. 2011;32:198-203.

6. Melzack R, Taenzer P, Feldman P, Kinch RA. Labour pain is still painful after prepared childbirth training. Can Med Assoc J. 1981;125:357-63.

7. Hess PE, Pratt SD, Lucas TP, Miller CG, Corbett T, Oriol N, et al Predictors of breakthrough pain during labor epidural analgesia. Anesth Analg. 2001;93:414-8

8. Benavides L, Wu JM, Hundley AF, Ivester TS, Visco AG. The impact of occiput posterior fetal head position on the risk of anal sphincter injury in forceps-assisted vaginal deliveries. Am J Obstet Gynecol. 2005;192:1702-6.

9. Panni MK, Segal S. Local anesthetic requirements are greater in dystocia than in normal labor. Anesthesiology. 2003;98:957-63.

10. Hildingsson I, Karlström A, Nystedt A. Women's experiences of induction of labour-findings from a Swedish regional study. Aust N Z J Obstet Gynaecol. 2011;51:151-7.

11. Melzack R, Bélanger E. Labour pain: correlations with menstrual pain and acute low-back pain before and during pregnancy. Pain. $1989 ; 36: 225-9$

12. Meredith $P$, Ownsworth $T$, Strong J. A review of the evidence linking adult attachment theory and chronic pain: presenting a conceptual model. Clin Psychol Rev. 2008;28:407-29.

13. Davies KA, MacFarlane GJ, McBeth J, Morriss R, Dickens C. Insecure attachment style is associated with chronic widespread pain. Pain. 2009;143:200-5.

14. Porter LS, Davis D, Keefe FJ. Attachment and pain: recent findings and future directions. Pain. 2007;128:195-8.

15. Craig AD. A new view of pain as a homeostatic emotion. Trends Neurosci. 2003;26:303-7.

16. Kolb LC. Attachment behavior and pain complaints. Psychosomatics. 1982;23:413-25

17. Feeney JA, Ryan SM. Attachment style and affect regulation: relationships with health behavior and family experiences of illness in a student sample. Health Psychol. 1994;13:334-45.

18. Bowlby J. Attachment and loss, Vol. I, Attachment. $2^{\text {nd }}$ ed. New York: Basic Books; 1982.

19. Bartholomew K, Horowitz LM. Attachment styles among young adults: a test of a four-category model. J Pers Soc Psychol. 1991;61:226-44.

20. Meredith P, Strong J, Feeney JA. The relationship of adult attachment to emotion, catastrophizing, control, threshold and tolerance, in experimentally-induced pain. Pain. 2006:120:44-52.

21. McWilliams LA, Cox BJ, Enns MW. Impact of adult attachment styles on pain and disability associated with arthritis in a nationally representative sample. Clin J Pain. 2000;16:360-4.

22. MacDonald G, Kingsbury R. Does physical pain augment anxious attachment? J Soc Pers Relat. 2006;23:291-304.

23. Ciechanowski $P$, Sullivan $M$, Jensen $M$, Romano J, Summers $H$. The relationship of attachment style to depression, catastrophizing and health care utilization in patients with chronic pain. Pain. 2003;104:62737.

24. Meredith P, Strong J, Feeney JA. Adult attachment, anxiety, and pain self-efficacy as predictors of pain intensity and disability. Pain. 2006;123:146-54.

25. Meredith P, Strong J, Feeney JA. Adult attachment variables predict depression before and after treatment for chronic pain. Euro $\mathrm{J}$ Pain. 2007; 11:164-70.

26. Canavarro MC, Dias $P$, Lima V. A avaliação da vinculação no adulto: uma revisão crítica a propósito da aplicação da Adult Attchment Scale-R (AAS-R) na população portuguesa. Psicologia. 2006;20:11-36.

27. Collins NL, Read SJ. Adult attachment, working models, and relationship quality in dating couples. J Pers Soc Psychol. 1990;58:644-63.

28. Cohen J, Cohen P, West SG, Aiken LS. Applied multiple regression/ correlation analysis for the behavioral sciences. $3^{\text {rd }}$ ed. Mahwah Lawrence Erlbaum; 2003.

29. Raphael-Leff J. Pregnancy: the inside story. London: Jason Aronson 1995.

30. Stern D. The motherhood constellation. A unified view of parent-infant psychotherapy. New York: Basic Books; 1995.

31. Hiltunen $P$, Raudaskoski $T$, Ebeling $H$, Moilanen I. Does pain relief during delivery decrease the risk of postnatal depression? Acta Obstet Gynecol Scand. 2004:83:257-61.

32. Weisman O, Granat A, Gilboa-Schechtman E, Singer M, Gordon I, Azulay $\mathrm{H}$, et al. The experience of labor, maternal perception of the infant, and the mother's postpartum mood in a low-risk community cohort. Arch Womens Ment Health. 2010;13:505-13.

33. Corli O, Grossi E, Roma G, Battagliarin G. Correlation between subjective labour pain and uterine contractions: a clinical study. Pain 1986;26:53-60

34. Ranasinghe JS, Birnbach DJ. Progress in analgesia for labor: focus on neuroaxial blocks. Int J Womens Health. 2010;1:31-43.

35. Leone S, Di Cianni S, Casati A, Fanelli G. Pharmacology, toxicology, and clinical use of new long acting local anesthetics, ropivacaine and levobupivacaine. Acta Biomed. 2008;79:92-105.

36. Lilker S, Rofaeel A, Balki M, Carvalho JC. Comparison of fentanyl and sufentanil as adjuncts to bupivacaine for labor epidural analgesia. $\mathrm{J}$ Clin Anesth. 2009;21:108-12.

37. Wallace P, Gotlib IA. Marital adjustment during the transition to parenthood: stability and predictors of change. J Marriage Fam. 1990;52:21-9.

38. Davenport-Slack B, Boylan $\mathrm{CH}$. Psychological correlates of childbirth pain. Psychosom Med. 1974;36:215-23.

39. Nettelbladt P, Fagerström CF, Uddenberg N. The significance of reported chilbirth pain. J Psychosom Res. 1976;20:215-21.

40. Hess PE, Pratt SD, Soni AK, Sarna MC, Oriol NE. An association between severe labor pain and cesarean delivery. Anesth Analg. 2000;90:881-6.

41. Chakour MC, Gibson SJ, Bradbeer M, Helme RD. The effect of age on A delta and C-fibre thermal pain perception. Pain. 1996;64:143-52.

42. Beebe KR, Lee KA, Carrieri-Kohlman V, Humphreys J. The effects of childbirth self-efficacy and anxiety during pregnancy on prehospitalization labor. J Obstet Gynecol Neonatal Nurs. 2007;36:410-8.

43. Da Costa D, Drista M, Larouche J, Brender W. Psychosocial predictors of labor/delivery complications and infant birth weight: a prospective multivariate study. J Psychosom Obstet Gynaecol. 2000;21:137-48.

44. Joseph KS, Fahey J, Dendukuri N, Allen VM, O'Campo P, Dodds L, et al. Recent changes in maternal characteristics by socioeconomic status. $J$ Obstet Gynaecol Can. 2009;31:422-33

45. Christiaens W, Verhaeghe M, Bracke P. Pain acceptance and personal control in pain relief in two maternity care models: a cross-national comparison of Belgium and the Netherlands. BMC Health Serv Res. 2010;10:268

46. O'Brien WF. The role of prostaglandins in labor and delivery. Clin Perinatol. 1995;22:973-84.

47. Husslein P, Fuchs AR, Fuchs F. Oxytocin and prostaglandin plasma concentrations before and after spontaneous labor: evidence of involvement of prostaglandins in the mechanism of placental separation. Wien Klin Wochenschr. 1983:95:367-71.

48. Odent M. New reason and new ways to study birth physiology. Int $J$ Gynaecol Obstet. 2001;75:S39-45

49. Bydlowsky M. Le regard intérieur de la femme enceinte, transparence psychique et représentation de l'objet interne. Devenir. 2001;13:41-52.

50. Ravitz P, Maunder R, Hunter J, Sthankiya B, Lancee W. Adult attachment measures: a 25-year review. J Psychosomatic Res. 2010;69:419-32.

51. Alder J, Stadlmayr W, Tschudin S, Bitzer J. Post-traumatic symptoms after childbirth: what should we offer? J Psychsom Obstet Gynaecol. 2006;27:107-12

52. Ayers S, Joseph S, McKenzie-McHarg K, Slade P, Wijma K. Posttraumatic stress disorder following childbirth: current issues and recommendations for future research. J Psychosom Obstet Gynaecol. 2008;29:240-50 
José Manuel COSTA MARTINS, Carlos Fernandes da SILVA, Marco PEREIRA, Henriqueta MARTINS, Célia OLIVEIRA, Alexandra PUGA, Rui COELHO, Jorge TAVARES

\section{Women's Attachment as a Predictor of Pain During Labour and Post-Delivery: a Prospective Observational Study}

Acta Med Port 2014:27:692-699

Publicado pela Acta Médica Portuguesa, a Revista Científica da Ordem dos Médicos

Av. Almirante Gago Coutinho, 151

1749-084 Lisboa, Portugal.

Tel: +351218428215

E-mail: submissao@actamedicaportuguesa.com

www.actamedicaportuguesa.com

ISSN:0870-399X | e-ISSN: 1646-0758

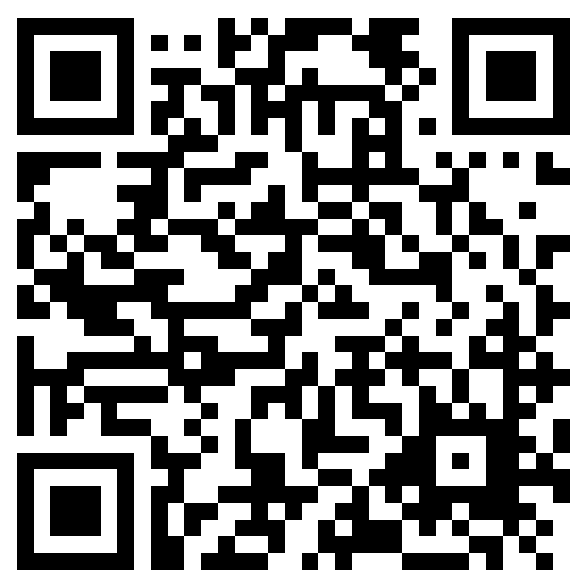

